\title{
BMJ Open Self-management of cardiac pain in women: an evidence map
}

\author{
Monica Parry, ${ }^{1}$ Ann Kristin Bjørnnes, ${ }^{1,2}$ Hance Clarke, ${ }^{3}$ Lynn Cooper, ${ }^{4}$ \\ Allan Gordon, ${ }^{5}$ Paula Harvey, ${ }^{6,7}$ Chitra Lalloo, ${ }^{8}$ Marit Leegaard, ${ }^{2}$ Sandra LeFort, ${ }^{9}$ \\ Judith McFetridge-Durdle, ${ }^{10}$ Michael McGillion, ${ }^{11}$ Sheila O'Keefe-McCarthy, ${ }^{12}$ \\ Jennifer Price, ${ }^{7}$ Jennifer Stinson, ${ }^{1,8}$ J Charles Victor, ${ }^{13}$ Judy Watt-Watson ${ }^{1}$
}

To cite: Parry M,

Bjørnnes AK, Clarke $\mathrm{H}$, et al. Self-management of cardiac pain in women: an evidence map. BMJ Open 2017;7:e018549. doi:10.1136/ bmjopen-2017-018549

- Prepublication history for this paper is available online. To view these files please visit the journal online (http://dx.doi. org/10.1136/bmjopen-2017018549).

Received 7 July 2017 Revised 10 0ctober 2017 Accepted 2 November 2017

CrossMark

For numbered affiliations see end of article.

Correspondence to Dr Monica Parry; monica.parry@utoronto.ca

\section{ABSTRACT}

Objective To describe the current evidence related to the self-management of cardiac pain in women using the process and methodology of evidence mapping.

Design and setting Literature search for studies that describe the self-management of cardiac pain in women greater than 18 years of age, managed in community, primary care or outpatient settings, published in English or a Scandinavian language between 1 January 1990 and 24 June 2016 using AMED, CINAHL, ERIC, EMBASE, MEDLINE, Proquest, Psychlnfo, the Cochrane Library, Scopus, Swemed+, Web of Science, the Clinical Trials Registry, International Register of Controlled Trials, MetaRegister of Controlled Trials, theses and dissertations, published conference abstracts and relevant websites using GreyNet International, ISI proceedings, BIOSIS and Conference papers index. Two independent reviewers screened using predefined eligibility criteria. Included articles were classified according to study design, pain category, publication year, sample size, per cent women and mean age.

Interventions Self-management interventions for cardiac pain or non-intervention studies that described views and perspectives of women who self-managed cardiac pain.

Primary and secondary outcomes measures Outcomes included those related to knowledge, self-efficacy, function and health-related quality of life.

Results The literature search identified 5940 unique articles, of which 220 were included in the evidence map. Only $22 \%(n=49)$ were intervention studies. Sixty-nine per cent $(n=151)$ of the studies described cardiac pain related to obstructive coronary artery disease (CAD), $2 \%(n=5)$ non-obstructive $C A D$ and $15 \%(n=34)$ postpercutaneous coronary intervention/cardiac surgery. Most were published after 2000, the median sample size was 90 with $25 \%-100 \%$ women and the mean age was 63 years.

Conclusions Our evidence map suggests that while much is known about the differing presentations of obstructive cardiac pain in middle-aged women, little research focused on young and old women, non-obstructive cardiac pain or self-management interventions to assist women to manage cardiac pain.

PROSPERO registration number CRD42016042806.

\section{BACKGROUND}

In 2015, more than 110 million people worldwide were affected by coronary artery

\section{Strengths and limitations of this study}

This evidence map provides an overview of a broad range of research based on a systematic search of 20 databases including grey literature sources published in English or a Scandinavian language between 1 January 1990 and 24 June 2016.

- Including only studies published in English or Scandinavian language may be seen as a limitation; however, we chose to include a robust search of the grey literature in an attempt to reduce a potential publication bias.

- Despite having healthcare providers and researchers involved in establishing the scope of the evidence map, our search strategy may not have targeted what women themselves see as the most important aspects of the self-management of cardiac pain.

- Additional search terms and keywords (eg, breathlessness, fatigue, sleep problems) and emotional sequelae (eg, anxiety, depression) may have identified additional self-management interventions targeted to cardiac pain and symptoms in women.

- This comprehensive evidence map identified evidence gaps and future research needs specifically focused on the self-management of cardiac pain in women.

disease $(\mathrm{CAD}),{ }^{1}$ and the number is expected to increase over the next decades. ${ }^{2}$ CAD is increasing in women less than 55 years of age due to rising obesity and diabetes rates. ${ }^{3}$ In 2013, 30\% more women died of CAD than cancer (including breast cancer) in the USA. ${ }^{4}$ According to most recent mortality statistics in Europe $^{5}$ (2015), CAD is the most common cause of death and accounts for $20 \%$ of all deaths among women.

Cardiac pain has been considered the primary indicator of $\mathrm{CAD},{ }^{6}$ and each year 4.5 million individuals are evaluated for cardiac pain in emergency departments in the USA. ${ }^{7}$ Cardiac pain disproportionately burdens more women than men, and women have a varied pattern and distribution of pain 
symptoms associated with both obstructive and non-obstructive CAD. ${ }^{89}$ Women also have a higher prevalence of clinically relevant cardiac pain after percutaneous coronary interventions (PCIs) and cardiac surgery and report more persistent pain of moderate to severe intensity up to 2 years after cardiac surgery. ${ }^{10-12}$ Poorly controlled acute pain (ischaemic and procedural) is a risk factor for persistent pain, a debilitating complication for women following cardiac surgery. ${ }^{13} 14$

The identification and management of cardiac pain associated with CAD are vital to minimise risk of a major adverse cardiac event (MACE). Women with obstructive and non-obstructive $\mathrm{CAD}$ have cardiac pain that differs from that of men. Women describe their pain as sharp and burning, with additional symptoms of discomfort in the jaw, neck, shoulders, arms, back and epigastric area. ${ }^{68}$ Women's pain and symptoms vary in frequency and distribution, making it difficult for them to interpret as cardiac specific. ${ }^{8}{ }^{15}$ Non-obstructive CAD (cardiac syndrome $\mathrm{X}$ ) is angina-like chest discomfort without evidence of coronary artery obstruction. ${ }^{16}$ Non-obstructive $\mathrm{CAD}$ is more prevalent in younger, middle-aged women and evidence suggests that more extensive, non-obstructive $\mathrm{CAD}$, hypertension and diabetes are associated with MACE similar to those with obstructive CAD. ${ }^{9} 17$ These women suffer from persistent and incapacitating cardiac pain, are at risk for impaired function, depression, poor health-related quality of life (HRQL) and death. ${ }^{18}$ They are also frequent users of healthcare services (emergency room, hospitalisation and repeat diagnostic evaluation). ${ }^{19}$

The risk of future coronary events for women who present with cardiac pain, additional symptoms and/or cardiac pain equivalents can be classified into risk categories that can be used to guide further assessment and evaluation. ${ }^{20}{ }^{21}$ In addition to having difficulty interpreting cardiac pain, women minimise their symptoms, prefer to consult with family and friends and have caring responsibilities and concerns for their family. ${ }^{22}$ As a result, women delay assessment and diagnostic evaluation ${ }^{23}$; the time from symptom onset to emergency department arrival for women is $85-320 \mathrm{~min}$, and this has not changed in the last decade. ${ }^{24}$ Over $25 \%$ of women will die within a year of their first myocardial infarction (MI) compared with 19\% of men, and $47 \%$ of women will die within 5 years of their first MI compared with $36 \%$ of men. ${ }^{25}$

The under-recognition of women's symptoms as well as the difficulty in diagnosing cardiac pain in women contribute to poorer outcomes and greater mortality rates in women as compared with men. ${ }^{6}$ Outcomes are also associated with a person's ability to self-manage their condition in everyday life. A variety of new skills have to be learnt: to comply with medication regimes, to establish and sustain new and healthier lifestyle routines, monitor and manage symptoms and recognise when to seek help when symptoms occur. ${ }^{26}$ Self-management programmes are designed to allow people to take an active part in the management of their condition through problem solving, decision making, action planning, self-tailoring and the formation of patient-provider partnerships. ${ }^{27} 28$ Due to the complexity of cardiac pain in women, there is an increased need to develop mechanisms to assist women to recognise and manage their pain. We conducted an comprehensive review of the literature to understand the current body of knowledge on self-management programmes for women with cardiac pain using methods described by the Evidence for Policy and Practice Information (EPPI) and the Coordinating Centre at the Institute of Education. ${ }^{29-33}$ In this paper, we will describe the first step in the EPPI review process, to establish the current evidence related to the self-management of cardiac pain in women using the process and methodology of evidence mapping.

\section{METHODS}

The main purpose of evidence mapping is to provide an overview of a broad range of research and identify evidence gaps and future research needs. ${ }^{34}$ The evidence map is broad in scope and is primarily focused on identifying and describing the characteristics of the evidence base. ${ }^{35}$ It is the first step in conducting an integrated mixed-methods systematic review, ${ }^{29-33}$ and it does not necessarily include quality appraisal of the included studies. ${ }^{36}$ Six steps were used to construct an evidence map of cardiac pain in women ${ }^{37}$ : (1) identify the scope of the evidence map; (2) define the key variables; (3) establish a comprehensive search strategy; (4) identify study inclusion and exclusion criteria; (5) systematically retrieve, screen and classify the evidence; and (6) report the findings in an evidence map.

\section{Identify the scope of the evidence map}

The initial scope of the work was established by the research team to focus on three types of cardiac pain in women: (1) obstructive CAD, (2) non-obstructive CAD and (3) postprocedure (PCI and cardiac surgery). The research question and the study eligibility criteria were discussed in a consultation session with healthcare providers (physicians and nurses) and researchers working in cardiology, cardiac surgery and adult multidisciplinary chronic pain clinics. An overarching review question was established and purposefully kept broad to ensure a comprehensive review of the evidence: What is known about the self-management of cardiac pain in women? This question could be answered by a broad range of quantitative and qualitative evidence, including systematic reviews, randomised controlled trials (RCTs), cohort studies, cross-sectional, case control studies and case series/reports.

\section{Define the key variables}

We used the PICO framework ${ }^{38}$ to focus our research question and to facilitate the literature search. The PICO question elements included population, intervention, comparison and outcomes. Keywords and the National Library of Medicine's Medical Subject Headings (MeSH) were combined under the three PICO categories: $(\mathrm{P})$ 
Table 1 PICO search strategy

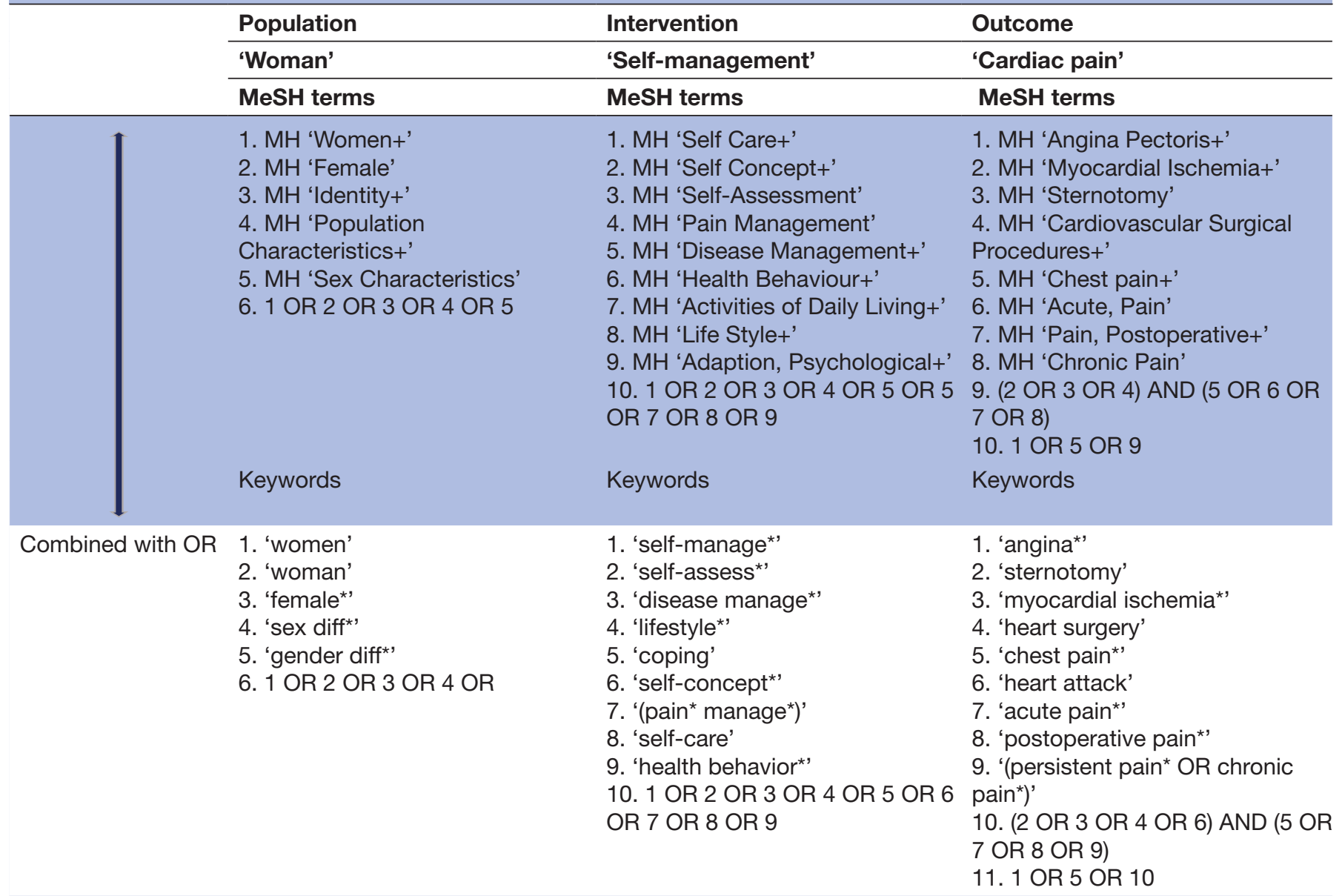

Combined with AND

${ }^{*}$ Comparison: none.

$\mathrm{MeSH}$, Medical Subject Headings.

women, (I) self-management and (O) cardiac pain (table 1). In this instance, we did not search using a comparator to maintain breadth of our evidence map.

\section{Establish a comprehensive search strategy}

The literature on the self-management of cardiac pain in women was systematically searched using keywords and MeSH headings in accordance with the search criteria in the bibliographic databases. Publications needed to be available in English or a Scandinavian language and published between 1 January 1990 and 24 June 2016 (inclusive). Searches were conducted in July 2016 using selected databases: AMED (Allied and Complementary Medicine), CINAHL, ERIC, EMBASE, MEDLINE, Proquest, PsychInfo, the Cochrane Library, Scopus, Swemed + and Web of Science. For ongoing and recently completed clinical trials, we searched the Clinical Trials Registry, International Register of Controlled Trials and the MetaRegister of Controlled Trials. Grey literature sources included theses and dissertation, published conference abstracts and relevant websites using GreyNet International, ISI proceedings, BIOSIS and Conference papers index. Publication citations were exported from electronic search interfaces to Endnote.

\section{Identify study inclusion and exclusion criteria}

The inclusion criteria were kept broad, and studies were included if they focused on the self-management of cardiac pain in women or described the views and perspectives of women who had cardiac pain independent of the research design. Types of participants included women who were greater than 18 years of age with cardiac pain, managed in the community, primary care or outpatient settings. Types of outcomes included those related to knowledge, self-efficacy, physical and mental function, social and role function and HRQL. Lastly, the number of women included in the studies needed to be at least $25 \%$ to adequately represent the ratio of men and women who have cardiac disease. ${ }^{4}$

\section{Systematically retrieve, screen and classify the evidence}

Title and abstracts of all identified articles were screened in the first round. Studies were excluded if they were not about the self-management of cardiac pain in women 
or described the views and perspectives of women who had cardiac pain. A random sample of excluded studies $(\mathrm{n}=50)$ was discussed between the two reviewers to establish screening accuracy and to confirm understanding of the study eligibility criteria. The second round was based on the full-text screening and followed all the predefined study eligibility criteria. The articles were single-screened due to the large number and time constraints. If the reviewer was unsure about inclusion/exclusion of an article, the second reviewer was consulted to confirm inclusion/exclusion. The included articles were classified and described according to study design as per the hierarchy of evidence (ie, systematic reviews/meta-analyses, intervention studies (RCTs) and non-intervention studies (prospective, retrospective/case control and cross-sectional)) and according to pain category (ie, obstructive $\mathrm{CAD}$, non-obstructive $\mathrm{CAD}$, postprocedure $(\mathrm{PCI} /$ cardiac surgery) and mixed). To ensure that characteristics of primary research studies were not over-represented, descriptions of the systematic reviews and systematic reviews with meta-analyses were not included in the final evidence map. ${ }^{39}$

\section{Report the findings in an evidence map}

Only characteristics of the primary research studies (ie, country, study design, pain category, publication year, sample size, per cent women and mean age) were included in the final evidence map. Primary research study bubble plots (ie, weighted scatter plots) were used to graphically illustrate the relationships between: (1) per cent women, study design and type of cardiac pain across year of publication, weighted by sample size and (2) age and type of cardiac pain across year of publication, weighted by sample size. All analyses were performed using Stata statistical software V.13. ${ }^{40}$

\section{RESULTS \\ Identification of studies}

In total, 6582 eligible citations were identified from searching commercially available bibliographic databases and grey literature sources (Figure 1). After the first screening, a total of 1368 citations were deemed to meet the eligibility criteria. Full-text reports were obtained and processed for 1125 (82\%) of the citations. Seventy-four per cent $(n=837)$ of these did not meet the eligibility criteria mainly because the outcomes were not related to cardiac pain or the number of women included was less than $25 \%$. In addition, $6 \%(\mathrm{n}=68)$ were excluded because they were systematic reviews or systematic reviews with meta-analyses. Twenty per cent $(n=220)$ were primary research studies and were included in the final evidence map: 22\% ( $\mathrm{n}=49)$ were intervention studies (RCTs) and $78 \%(\mathrm{n}=171)$ were non-intervention studies (prospective, retrospective/case control and cross-sectional).

Thirty-three per cent $(n=73)$ of the studies were identified through grey literature sources. The majority of

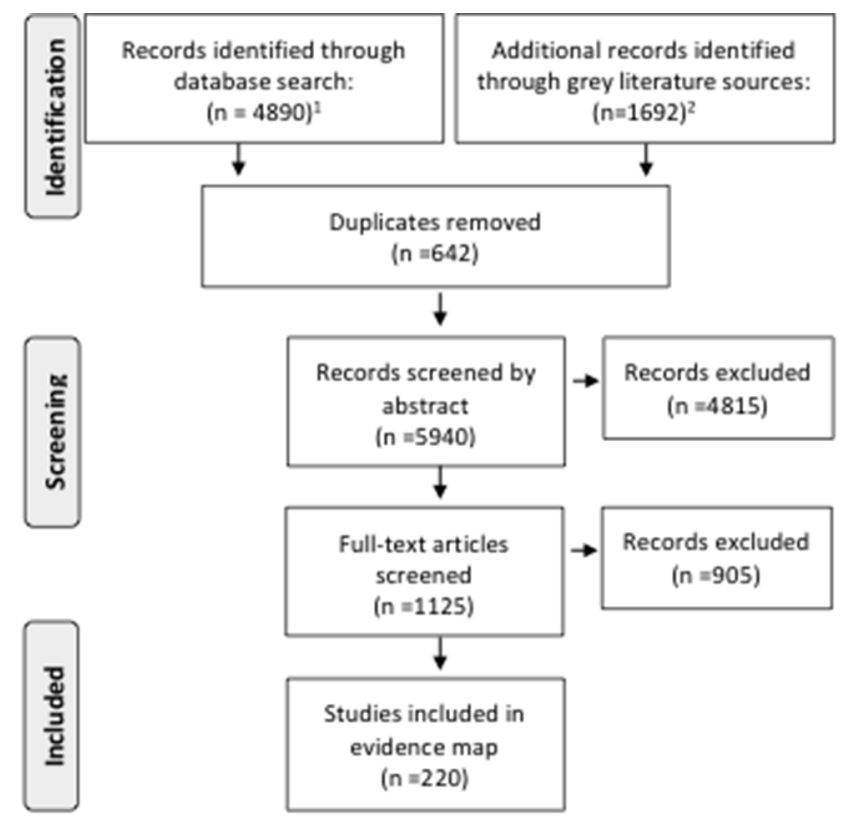

${ }^{1}$ Records identified through database search: AMED (7), CINAHL (42), ERIC (1), EMBASE (1251), MEDLINE (1014), Proquest (106), Psychlnfo (52), The Cochrane Library (53), Scopus (742), Swemed+ (65), Web of Science core collection (1557).

${ }^{2}$ Additional records identified through grey literature sources: BIOSIS Previews (489), Clinical Trails.gov (87), Conference papers index (35), GreyNet International (10), ISRCTN (69), Proquest Theses and Dissertation International (977), Public Health Grey Literature Sources Ontario Public Health Libraries Association (OPHLA) (15), WHO International Clinical Trials, Registery Platform (10).

Figure 1 Flow chart. 
these $(n=60,82 \%)$ were dissertations related to obstructive $\mathrm{CAD}$.

\section{Characteristics of the primary research studies}

Of the 220 primary research studies, 98 (45\%) were conducted in North America and $44(20 \%)$ in Western Europe. No relevant studies from the African continent and only one study from South America (ie, Brazil) were identified. Thirteen per cent $(n=29)$ of the studies were published before year 2000, 52\% ( $\mathrm{n}=114)$ between 2000 and 2010 and $35 \%(n=77)$ were published after 2010 . Sixtynine per cent $(n=151)$ of the included studies on cardiac pain in the evidence map represented obstructive CAD, $2 \%(\mathrm{n}=5)$ non-obstructive CAD, $15 \%(\mathrm{n}=34)$ post-PCI or cardiac surgery pain and $14 \%(\mathrm{n}=30)$ of studies were a mixed sample of obstructive CAD and post-PCI/cardiac surgery pain. Characteristics of the primary research studies according to pain category are outlined in table 2.

There were a total of 61891 participants (29 $552(48 \%)$ women) included across studies, and the mean age was 63 years (range $47-80$ years). The median sample size was 90 (range 7-7093), the mean proportion of women was 56\% and $58(26 \%)$ of studies included only women $(\mathrm{n}=15071)$. The relationship between the per cent women, study design, type of cardiac pain and year of publication are depicted in figure 2. Figure 3 illustrates the relation between mean age and sample size across years of publication and pain categories.

\section{Characteristics of the intervention studies}

Forty-nine (22\%) of the studies on cardiac pain focused on interventions, including $33(67 \%)$ RCTs with parallel group design, 7 (14\%) RCT pilots and 9 (18\%) quasi-experimental RCTs. Twenty-six (53\%) of the RCTs assessed the effectiveness of interventions targeting men and women with obstructive CAD. Three RCTs $(6 \%)$ included women with non-obstructive CAD. Postprocedural pain was the main or secondary outcome of $7(14 \%$ (cardiac surgery: $\mathrm{n}=4$, PCI: $\mathrm{n}=2$, mixed: $\mathrm{n}=1$ ) ) RCTs, and $13(27 \%)$ RCTs had a mixed sample of both obstructive and post-PCI/cardiac surgery pain. Interventions investigating cardiac pain related to obstructive $\mathrm{CAD}$ and postprocedure (PCI/CABG) included 25\%-100\% of their sample as women. In comparison, interventions targeting cardiac pain due to non-obstructive CAD only included women (ie, no men). The RCTs evaluated outcomes of different self-management interventions that were broad and targeted cardiac pain and symptom management through complementary and alternative medicine (CAM) interventions or self-management support delivered in groups, over the Internet, face to face or with help of other educational resources (eg, information sheets, videos). The median duration of the interventions was 2 months (range $<1$ week to 24 months), and the median follow-up time was 4 months (range $<1$ week to 9 years). The interventions and outcomes according to pain category and year of publication are outlined in table 3 .
Patient-reported outcomes across the RCTs included cardiac pain frequency and/or intensity, bodily pain, HRQL or other psychosocial factors associated with cardiac pain including fatigue, stress, depressive symptoms, anxiety, catastrophising, coping, self-efficacy, sense of coherence and personality traits. A majority of the studies also included objective outcomes related to cardiac risk factors (eg, blood pressure, weight, cholesterol levels, blood glucose and ischaemic stress tests) and patient self-reports about health behaviours (eg, smoking, activity and dietary habits). The most common data collection methods used in approximately $90 \%$ of the intervention studies were validated self-reported questionnaires collected on site by the research team or sent out by mail. Outcomes were also extracted from medial charts or registries. Ten per cent of the studies collected data through telephone surveys or face-to-face interviews using standardised.

\section{Characteristics of non-intervention studies}

In total, we identified 171 non-intervention studies: 49 (29\%) prospective, $41(24 \%)$ retrospective and $78(46 \%)$ cross-sectional. In addition, three (2\%) studies had a case-control design (table 2). The majority $(\mathrm{n}=125,73 \%)$ of the non-intervention studies focused on women with obstructive CAD, $63(50 \%)$ of these were cross-sectional studies. Two (1\%) cross-sectional studies investigated cardiac pain and symptoms in women with non-obstructive CAD. Similar to the intervention studies, non-interventions studies investigating cardiac pain related to obstructive $\mathrm{CAD}$ and postprocedure (PCI/CABG) included $25 \%-100 \%$ of their sample as women, and all non-interventions studies in non-obstructive $\mathrm{CAD}$ included women only. Outcomes assessed were similar to those outcomes described for the intervention studies. Validated self-reported questionnaires were used in approximately $75 \%$ of the quantitative non-intervention studies, and $25 \%$ used structural interviews delivered face to face or by telephone. In addition, $52(30 \%)$ of the non-intervention studies used qualitative interviews (ie, semistructured or in-depth interview), and 11 (7\%) used focus group interviews to collect data. A combination of quantitative and qualitative methods was found in $11(7 \%)$ studies. The majority of the qualitative and mixed method studies were related to obstructive CAD ( $\mathrm{n}=54,73 \%)$ that explored women's cardiac pain and symptom experiences. Cardiac pain appraisal and pain self-management strategies were also investigated, primarily with a focus on prehospital delays, barriers/challenges (eg, knowledge deficits) or sequelae after the cardiac event (eg, anxiety, depression, fatigue) and impact on everyday life. Self-management strategies primarily included education and eHealth interventions and strategies targeted to CAM. No qualitative study was found to focus on women with non-obstructive CAD. Five studies explored women's experiences after cardiac surgery, and two studies explored women's experiences with cardiac rehabilitation in mixed samples of women after cardiac events (eg, MI and cardiac surgery). 


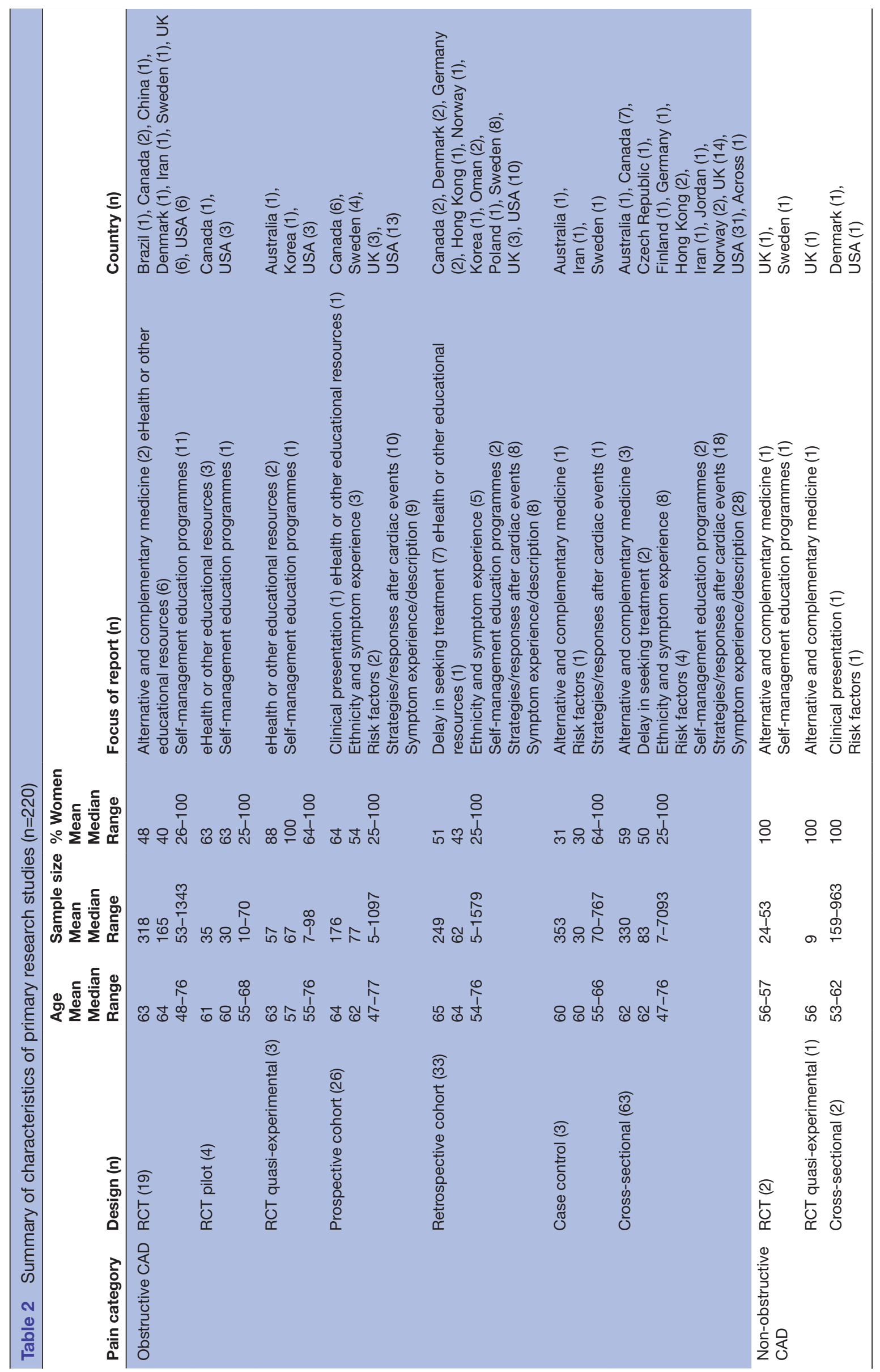



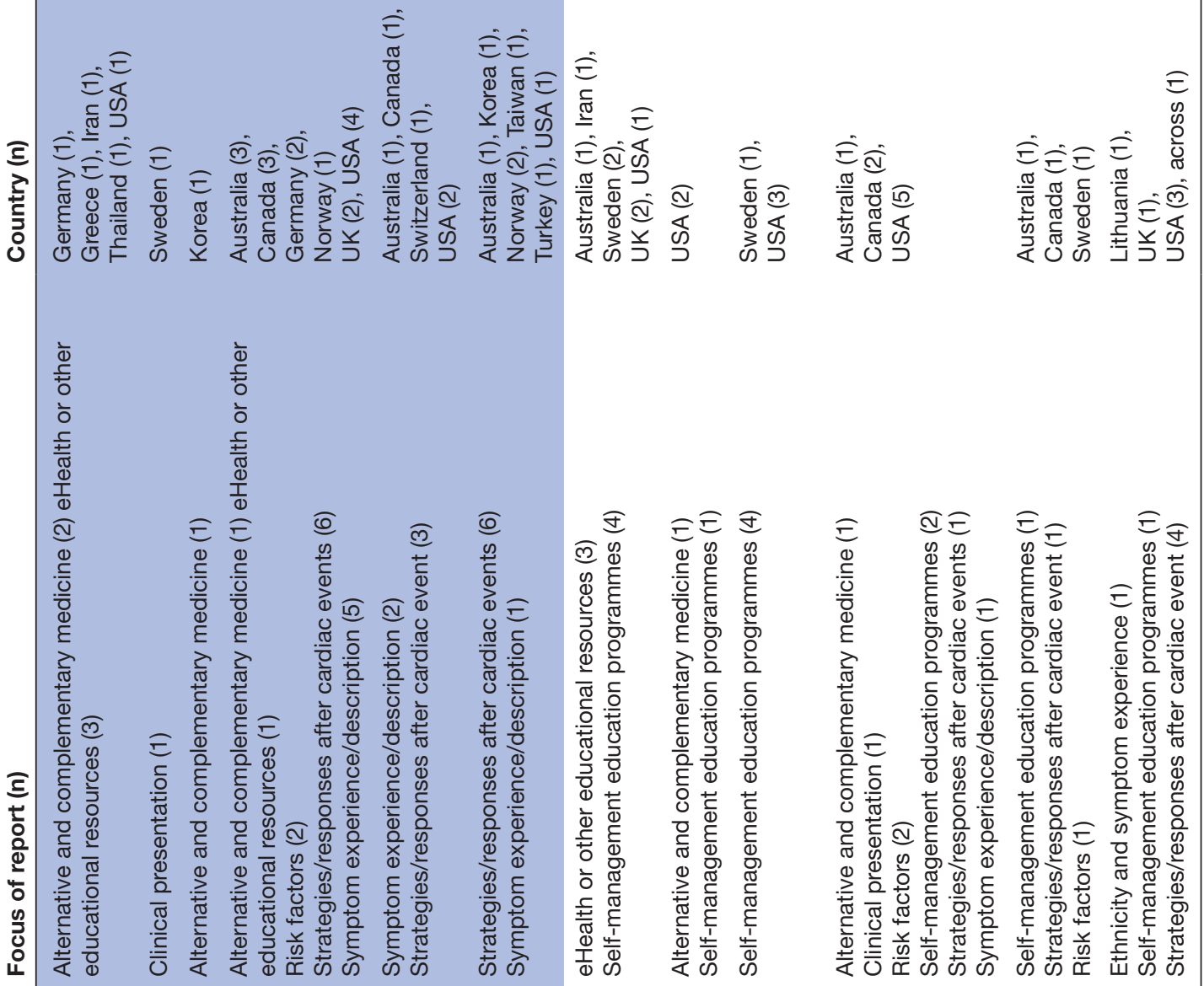

I $E$ E

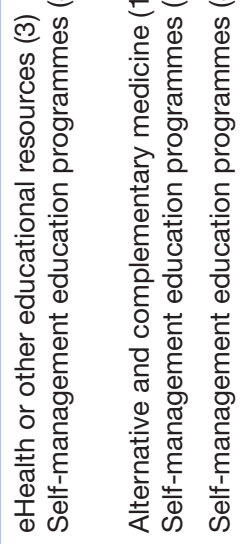

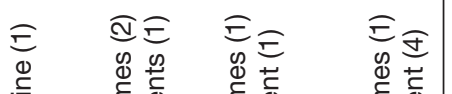

咅

$\stackrel{9}{\Phi}$

?

要

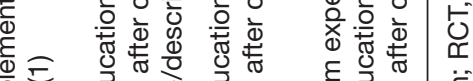

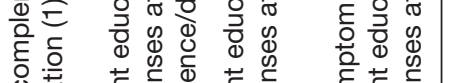

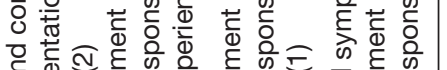

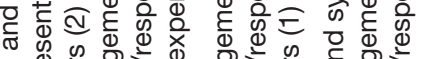

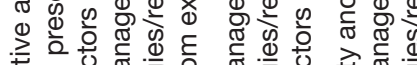

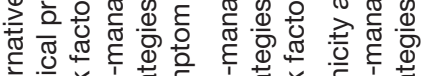

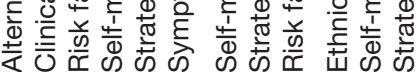

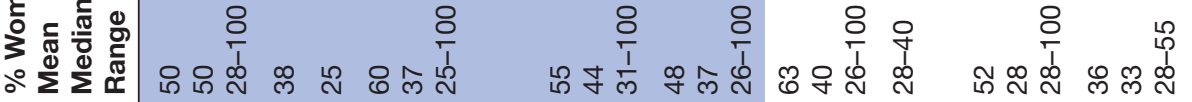
ำ

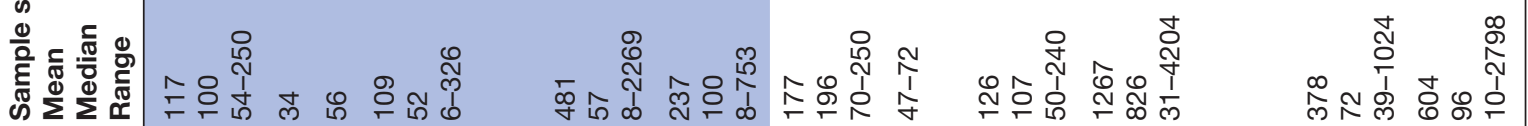
$\sqrt{2}$

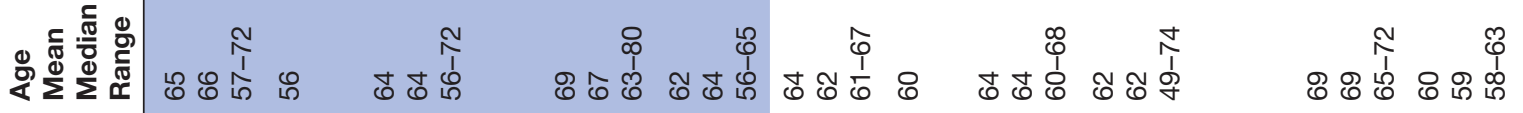
८ Бெ

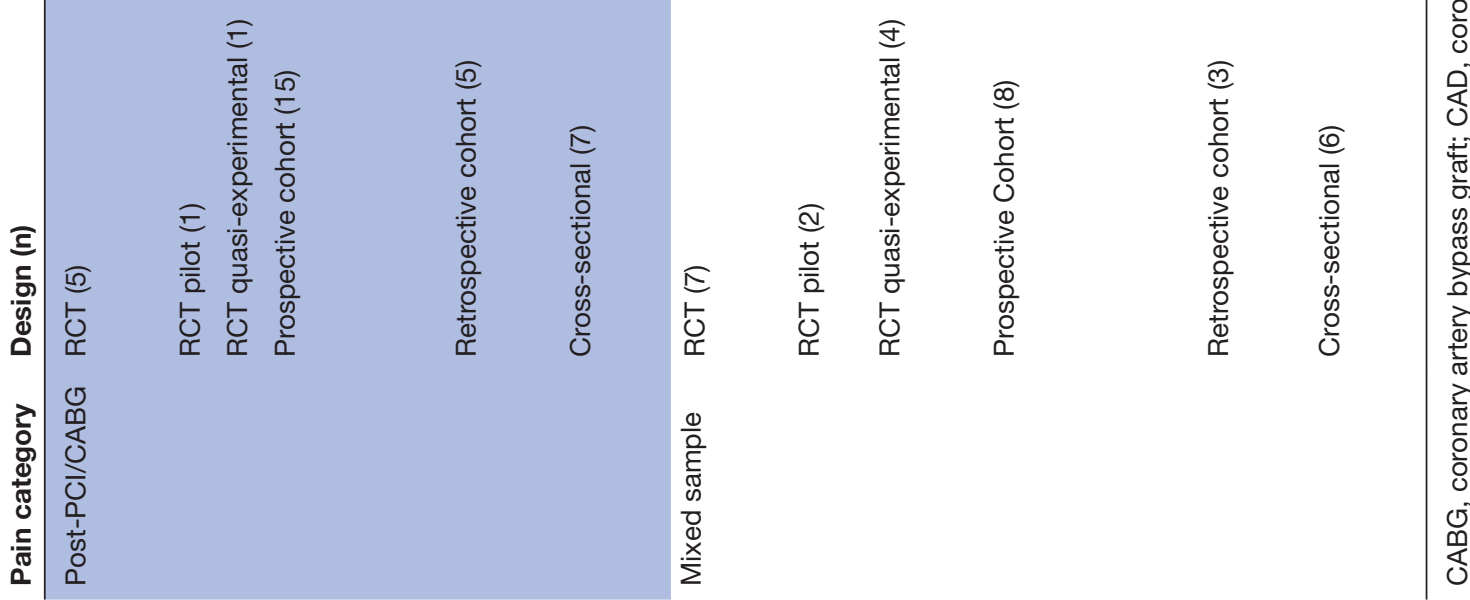




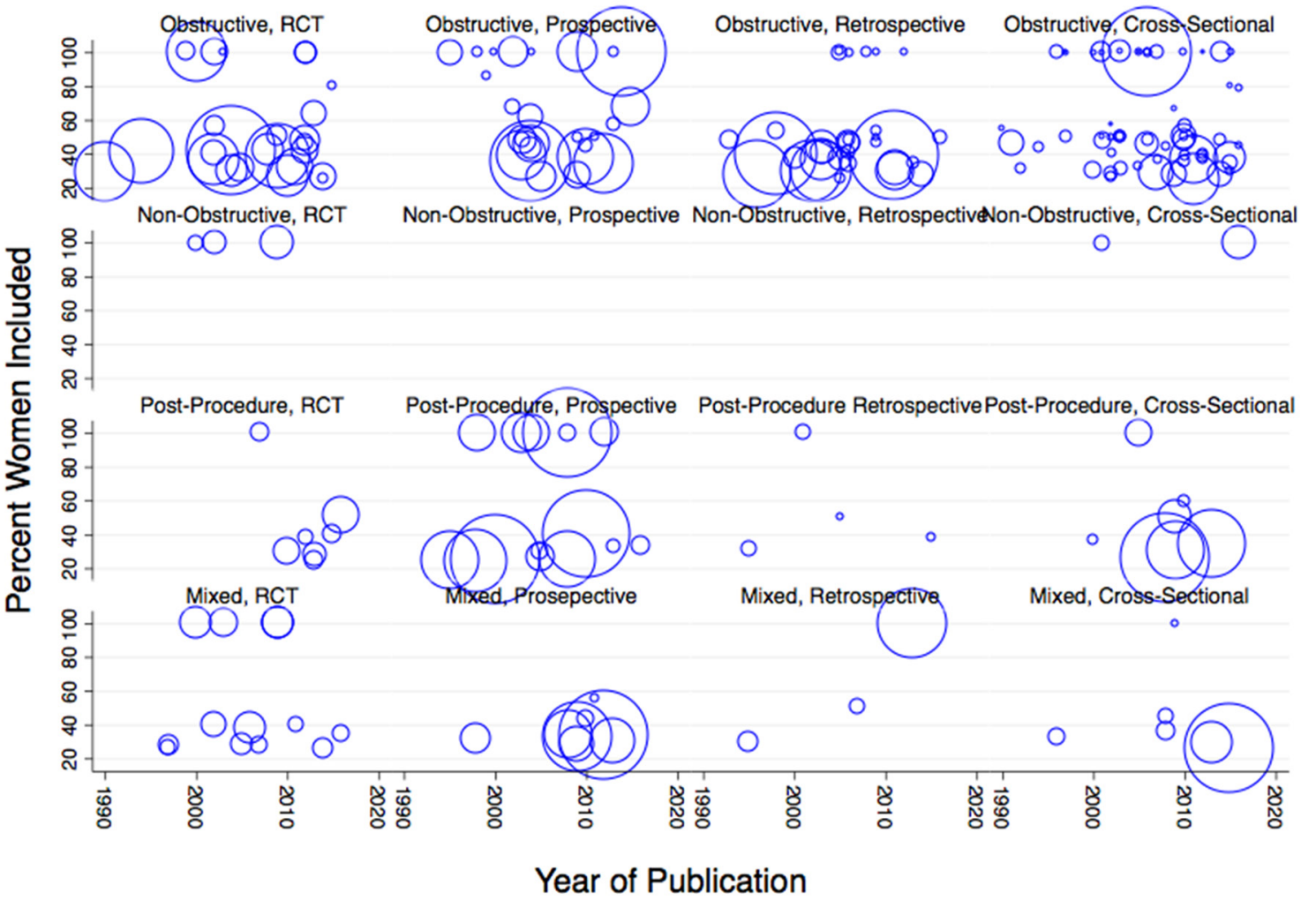

Figure 2 Percent women, study design and type of cardiac pain across year of publication, weighted by sample size. RCT, randomised controlled trial.

Seventeen (10\%) studies explored association between ethnicity and obstructive CAD descriptions and recognition in women, and most $(\mathrm{n}=10,58 \%)$ were cross-sectional studies. In addition, among studies conducted in the USA, the sample often included minority ethnic groups (eg, African-American, Hispanic), but outcomes were rarely reported for these groups separately.

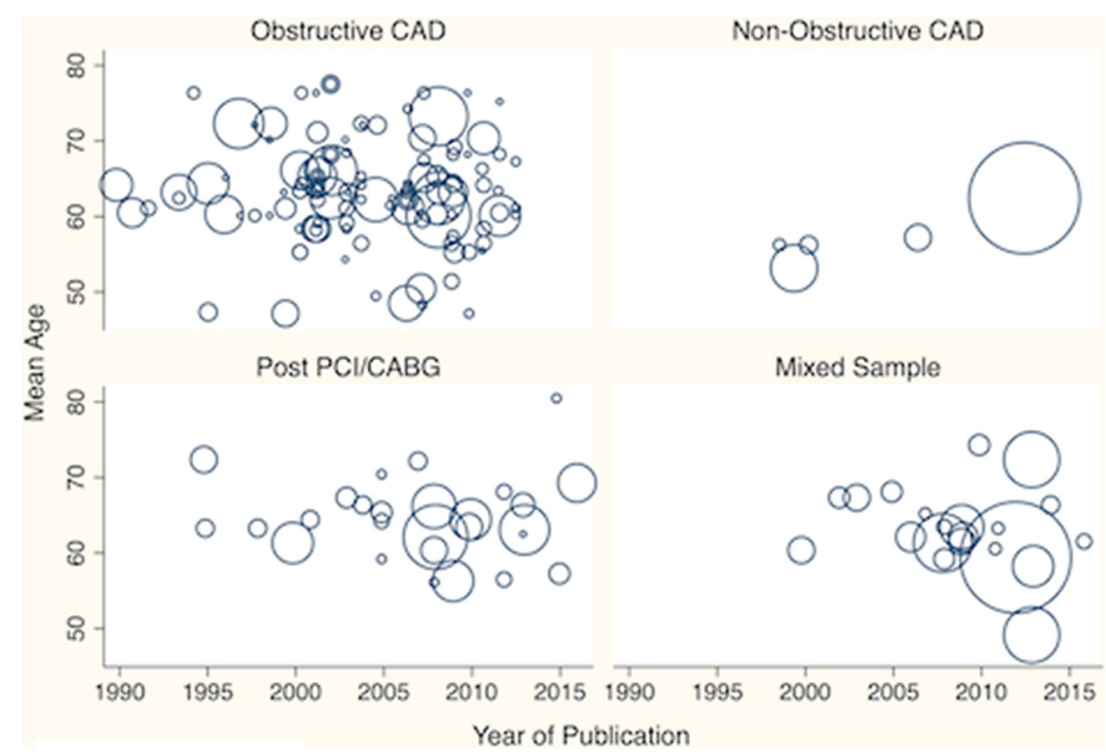

Figure 3 Age and type of cardiac pain across year of publication, weighted by sample size. CABG, coronary artery bypass graft; CAD, coronary artery disease; $\mathrm{PCl}$, percutaneous coronary intervention.

\section{DISCUSSION}

The studies included in our evidence map provide a very comprehensive broad overview of the evidence on the self-management of cardiac pain in women published between 1 January 1990 and 24 June 2016. Main results confirm those of the Committee on Women's Health Research ${ }^{41}$ suggesting that there has been some progress 


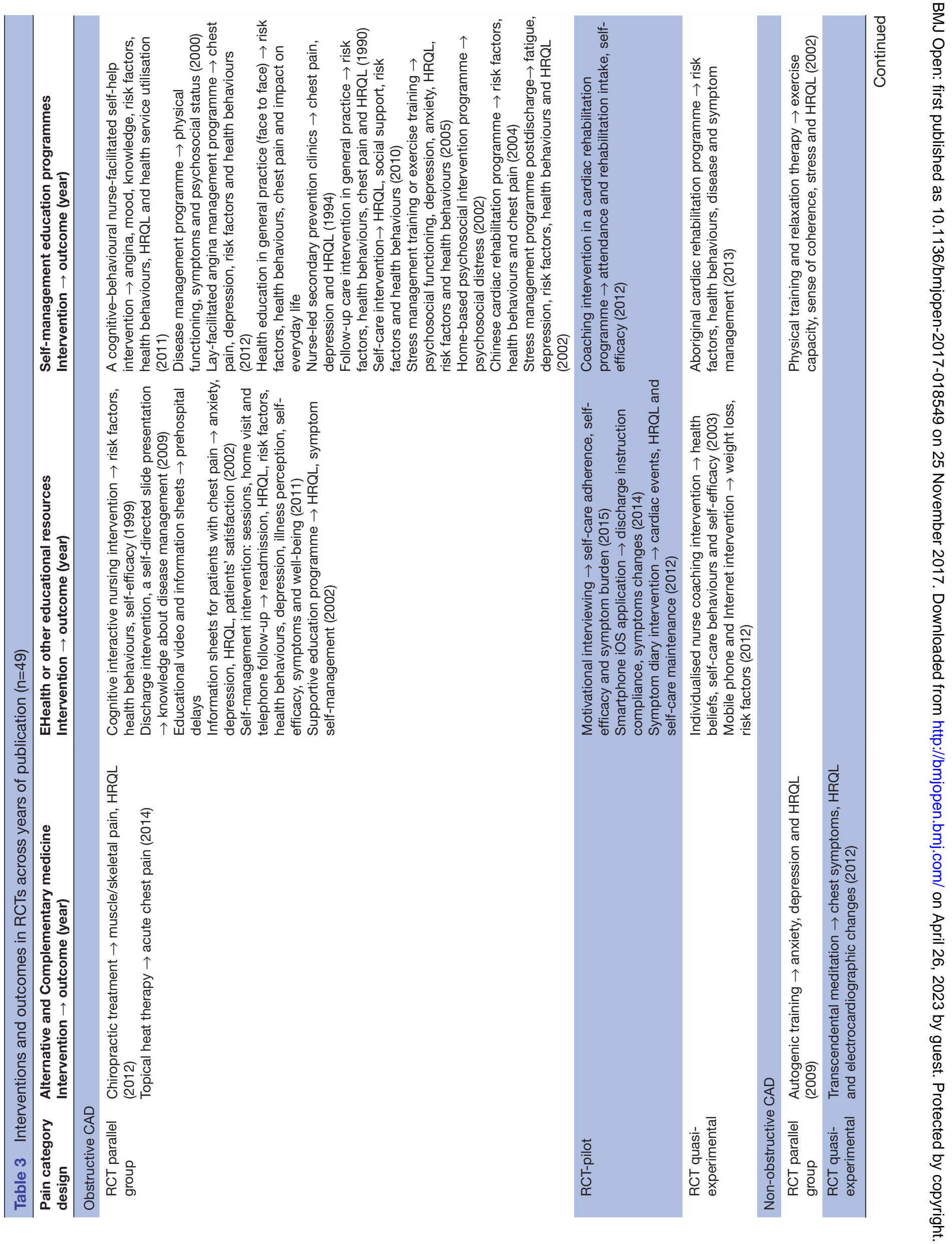




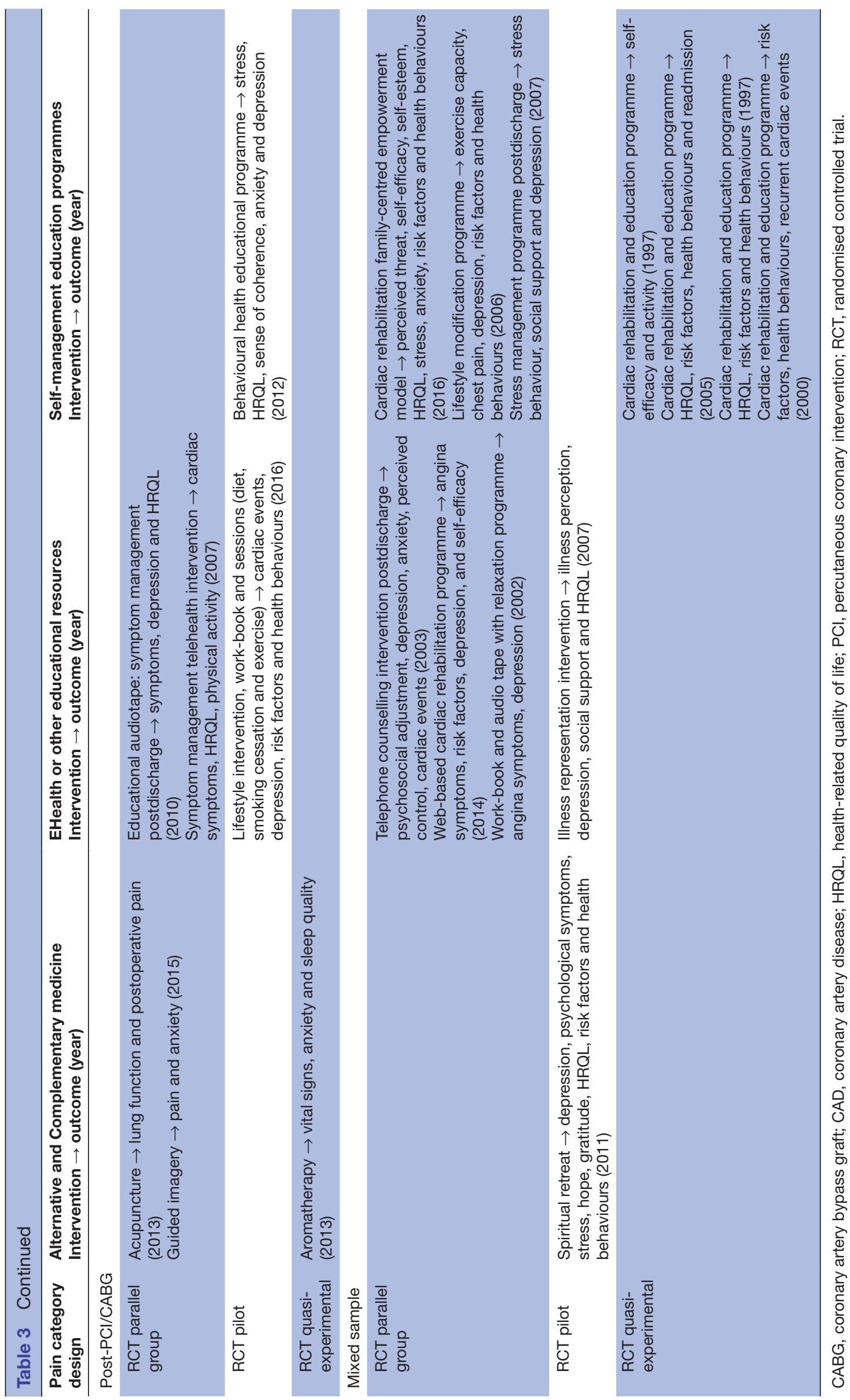


in the increased representation of women in cardiovascular health research and increased knowledge about atherosclerotic disease in women, such as sex differences in the pathophysiology of CAD, symptom presentation and clinical outcomes. However, our results are consistent with more recent evidence ${ }^{42} 43$ that suggests a general lack of research incorporating: (1) sex and gender, (2) women younger than 50 years and older than 75 years and (3) self-management interventions.

Sex and gender terms are not interchangeable. ${ }^{44}$ Sex refers to the anatomy of an individual's reproductive system, and gender refers to socially constructed characteristics of women and men based on behaviours, expressions and identities. ${ }^{45}$ We identified 57 (26\%) studies that included only women (1990 to September 2016) and 84 (38\%) studies that had fewer than $40 \%$ women in the total sample. Under-representation of women $(<25 \%)$ was one of the main reasons for exclusion of studies in our second screening, and this was to ensure that we had a representative sample of studies reflecting the ratio of men and women with cardiovascular disease. Thus, despite the reported progress in the increased representation of women in cardiovascular health research, our results suggest that this gap still exists and is supported by more recent evidence. ${ }^{46}$ In addition to sex, there is a need to identify and examine gender differences in self-management interventions for cardiac pain. Pilote and Norris reported that gender was associated with higher rates of recurrent acute coronary syndrome and MACE. ${ }^{47}$ Other psychosocial factors (eg, depression) have been linked to adverse outcomes after an $\mathrm{MI}^{48} ; 50 \%$ of women less than 50 years of age and $40 \%$ of women between 50 and 60 years of age have major depression. ${ }^{49}$ In addition to depression, women with premature MI are often from minority groups and have low socioeconomic status and exposure to sexual abuse during childhood. ${ }^{49}$ Researchers must consider the complex inter-relationships between the anatomical/physiological aspects, psychological processes and the person's interaction within the sociocultural context ${ }^{44}$ when designing self-management interventions a priori rather than adjusting for them in the analyses. $^{50}$

Over $25 \%$ of women will die within a year of their first MI compared with $19 \%$ men; and $47 \%$ women will die within 5 years of their first MI compared with $36 \%$ men. ${ }^{25}$ These disparities are associated with age, ethnicity and risk factor burden (eg, depression). ${ }^{51}$ These disparities lead to women delaying to seek medical care for their cardiac pain. ${ }^{23}$ In a recent integrated review including 23 studies in 17 different countries, ${ }^{52}$ older age, female gender, ethnicity, lower socioeconomic status and symptom knowledge deficits were associated with mean delay times of 3.4 hours. Only three studies in this review ${ }^{52}$ included a subanalysis by ethnicity, and these studies reported that Blacks, Asians, Hispanics and South Asians had longer delays in seeking medical care compared with Caucasians. Ethnicity and culture affect perceptions of chest pain and aspects of a woman's life that includes caregiving, education, employment and self-management practices. ${ }^{43}$ We found 17 studies that focused on ethnicity and symptom experience; a majority of these were cross-sectional studies conducted in North America and included women with African or Hispanic origins. Indigenous people experience greater cardiovascular disease burden, ${ }^{53}$ yet only one quasi-experimental RCT targeted indigenous women. ${ }^{54}$ This indicates that we have little research-based information on which to develop effective self-management interventions for non-Caucasians across all cardiac pain categories.

The majority of studies in the evidence map included women 50-75 years of age. In view of the increasing incidence of CAD and higher death rates in younger women with obstructive CAD compared with men, ${ }^{556}$ this research gap is disturbing. Women's increased risks for macrovascular or obstructive CAD are linked to higher obesity and diabetes rates, ${ }^{55}$ and diabetes also concurs an accelerated risk for microvascular or non-obstructive $\mathrm{CAD}$ in younger women. ${ }^{17}$ Healthcare costs attributable to non-obstructive cardiac pain are increasing, ${ }^{19}$ and the lack of recognition and assessment of early symptoms in younger women may underpin a negative trajectory. ${ }^{43}$ Younger women with CAD are more likely to have caregiving responsibilities, marital/family dysfunction and poorer perceived social support compared with men and older women. ${ }^{55}$ Our results suggest that we need to include women younger than 50 years and older than 75 years in self-management research related to cardiac pain.

A recent Scientific Statement from the American Heart Association $^{43}$ indicates that self-management interventions specifically tailored for women only are more effective. Self-management interventions allow people to take an active part in the management of their own conditions ${ }^{27}$ and are important predictors of successful behaviour change ${ }^{57}$ In addition to reducing pain, self-management interventions improve HRQL. ${ }^{58-63}$ Self-management is one of the six components of the chronic care model $(\mathrm{CCM}),{ }^{64-66}$ and personal efforts to engage in self-management cannot be made without consideration to other CCM components, such as the community and provider decision supports. We recommend using a strong theoretical model to guide the design and evaluation of self-management interventions focused on the sex and gendered aspects of cardiac pain in women. For example, the individual and family self-management theory targets context (condition-specific factors, physical and social environments), process (goal setting, self-monitoring, decision making, planning and engaging in specific behaviours, collaboration) and outcomes (health status, HRQL, $\operatorname{cost})^{6768}$ and could be used to design tailored interventions for women with cardiac pain.

Non-pharmacological interventions women used to self-manage obstructive and postprocedural cardiac pain included physical exercise and relaxation, cognitivebehavioural therapy, music, aromatherapy, acupuncture and peer support. Many of these interventions were often incorporated as part of rehabilitative treatment 
approaches. Psychological treatments were generally separated into theoretically based approaches (eg, acceptance-based and mindfulness therapy) and more specific techniques (eg, cognitive-behavioural therapy, relaxation and hypnosis). ${ }^{69}$ Non-pharmacological persistent pain interventions were in general about reducing pain intensity and pain interference and the disability associated with symptoms. ${ }^{69}$ In addition to cardiac pain frequency, outcomes emphasised HRQL and other biopsychosocial factors associated with cardiac pain. This is a promising direction for future research, particularly for women who experience cardiac pain without evidence of coronary artery obstruction or continue to have cardiac pain despite coronary interventions. Creating mechanisms to assist women to recognise and manage cardiac pain and symptoms and guide them to seek appropriate assessment and evaluation is absolutely necessary in future research studies. ${ }^{20} 70$ Although women are more likely to have cardiac pain in the absence of obstructive CAD, the evidence is inconclusive. ${ }^{71}$ For these women, elimination of physical causes of pain is not always possible. We found only five studies addressing cardiac pain in women with non-obstructive CAD; no qualitative study was found, suggesting little in-depth knowledge exists about how women describe, manage and make decisions about non-obstructive cardiac pain. Addressing this knowledge gap is essential before developing self-management interventions to meet the unique needs of these women. Cardiac pain is complex, and the need for holistic treatment approaches has been emphasised. ${ }^{72}$ In total, $19(9 \%)$ studies across cardiac pain categories and study designs focused on complementary approaches (ie, CAM) for cardiac pain. These interventions aligned with the complementary integrative medicine interventions for persistent pain summarised in a systematic review by Delgado $\mathrm{et} \mathrm{al.} .^{73}$ Only eight of the studies in our evidence map, including $2 \%(n=554)$ of the total trial participants in the 49 intervention studies, assessed the effect of CAM interventions in RCTs. This indicates that we are lacking strong evidence to routinely include CAM interventions in cardiac pain treatment strategies for women.

\section{Limitations}

This evidence map is based on a comprehensive and systematic search of 20 databases including grey literature sources. Despite the high number of potentially eligible studies, many were either not relevant to cardiac pain or the number of women included in the studies was too low. Including only studies published in English or Scandinavian language may be seen as a limitation. However, we chose to include a robust search of the grey literature in an attempt to reduce this potential publication bias. ${ }^{74}$ The articles in the second round of full-text screening were also single-screened, which may be seen as a limitation. However, if there was uncertainty about an article, a second reviewer was consulted to confirm inclusion/ exclusion.
Despite having healthcare providers and researchers involved in establishing the scope of the evidence map, our search strategy may not have targeted what women themselves see as the most important aspects of the self-management of cardiac pain. Cardiac pain is a subjective experience and is associated with physical symptoms (eg, breathlessness, fatigue, sleep problems) and emotional sequelae (eg, anxiety, depression). ${ }^{75}$ Additional search terms and keywords related to cardiac pain and symptoms may have increased our probability of identifying self-management interventions. The next step in the EPPI review process is to present results of this broad mapping and screening exercise to women with cardiac pain (obstructive CAD, non-obstructive CAD and postprocedure (PCI and cardiac surgery)), to reconfirm our search terms for a more targeted in-depth search and review including quality appraisal of intervention and non-intervention studies to enhance the self-management of cardiac pain in women.

\section{CONCLUSIONS}

We aimed to describe the current evidence related to the self-management of cardiac pain in women using the process and methodology of evidence mapping. It was not to present individual study results or synthesis of results, but to describe the process and methodology for creating an evidence map database, using the topic of self-management of cardiac pain in women. Results from this mapping process suggest that evidence about risk factors, clinical presentations and symptom experiences in women is emerging, particularly for middle-aged women with obstructive CAD. While much is known about the differing presentations of cardiac pain in women, not enough is known about young and old women, women with non-obstructive $\mathrm{CAD}$, and little has been done to help women manage their pain. Self-management intervention trials are lacking across all cardiac pain categories (obstructive $\mathrm{CAD}$, non-obstructive $\mathrm{CAD}$ and postprocedure (PCI and cardiac surgery)). Further research to develop mechanisms to assist women to recognise and manage cardiac pain, using a strong theoretical model to address contextual and process components of self-management, is needed.

\section{Author affiliations}

${ }^{1}$ Lawrence S Bloomberg Faculty of Nursing, University of Toronto, Toronto, Ontario, Canada

${ }^{2}$ Institute of Nursing and Health Promotion, Oslo and Akershus University College of Applied Sciences, Oslo, Norway

${ }^{3}$ Pain Research Unit, University Health Network, Toronto, Ontario, Canada ${ }^{4}$ Canadian Pain Coalition, Toronto, Ontario, Canada

${ }^{5}$ Wasser Pain Management Centre, Mount Sinai Hospital, Toronto, Ontario, Canada ${ }^{6}$ Department of Medicine, Women's College Hospital, Toronto, Ontario, Canada ${ }^{7}$ Women's College Hospital, Women's College Research Institute, Toronto, Ontario, Canada

${ }^{8}$ Hosp Sick Children, The Peter Gilgan Centre for Research and Learning, Toronto, Ontario, Canada

${ }^{9}$ School of Nursing, Memorial University of Newfoundland, St. John's,

Newfoundland, Canada

${ }^{10}$ College of Nursing, Florida State University, Tallahassee, Florida, USA 
${ }^{11}$ School of Nursing, McMaster University, Hamilton, Ontario, Canada

${ }^{12}$ Department of Nursing, Faculty of Applied Sciences, BrockUniversity, Toronto, Ontario, Canada

${ }^{13}$ Institute of Health Policy, Management and Evaluation, University of Toronto, Toronto, Ontario, Canada

Acknowledgements The authors would like to thank Ms Stephanie Xavier, who contributed to the search of the grey literature while a student in the Undergraduate Student Summer Research Program at the Lawrence S. Bloomberg Faculty of Nursing, University of Toronto, Ontario, Canada. The authors also thank Ms Ana Patricia Ayala and Ms Erica Lenton, two experienced information specialists at the Gerstein Science Information Centre at the University of Toronto, Toronto, Ontario, Canada, who were available for consultation during the search.

Contributors MP formulated the research question. AKB and MP devised the search strategy, in consultation with two experienced information specialists at the Gerstein Science Information Centre at the University of Toronto, Toronto, Ontario, Canada. AKB conducted the searches. AKB screened all titles, abstracts and full-text articles in consultation with MP. AKB extracted the data in consultation with MP. AKB and MP cowrote the manuscript. HC, LC, AG, PH, CL, ML, SL, JM-D, MM, SO-M, JP, $\mathrm{JS}, \mathrm{JCV}$ and JW-W critically reviewed the manuscript and made revisions prior to submission.

Funding This study was funded by a Canadian Institutes of Health Research Knowledge Synthesis Grant 362774. AKB was supported by a Tom Kierans International Post-Doctoral Fellowship from the Lawrence S. Bloomberg Faculty of Nursing, University of Toronto, Ontario, Canada.

\section{Competing interests None declared.}

Ethics approval Ethics approval was obtained from the Health Sciences Research Ethics Board at the University of Toronto, Ontario, Canada (protocol no. 33289).

Provenance and peer review Not commissioned; externally peer reviewed.

Data sharing statement All data in this evidence map are documented in the manuscript. No additional data are available.

Open Access This is an Open Access article distributed in accordance with the Creative Commons Attribution Non Commercial (CC BY-NC 4.0) license, which permits others to distribute, remix, adapt, build upon this work non-commercially, and license their derivative works on different terms, provided the original work is properly cited and the use is non-commercial. See: http://creativecommons.org/ licenses/by-nc/4.0/

(C) Article author(s) (or their employer(s) unless otherwise stated in the text of the article) 2017. All rights reserved. No commercial use is permitted unless otherwise expressly granted.

\section{REFERENCES}

1. Steel N. GBD 2015 Disease and Injury Incidence and Prevalence Collaborators. Global, regional, and national incidence, prevalence, and years lived with disability for 310 diseases and injuries, 19902015: a systematic analysis for the Global Burden of Disease Study 2015. Lancet 2016;388:1545-602.

2. Mathers CD, Loncar D. Projections of global mortality and burden of disease from 2002 to 2030. PLoS Med 2006;3:e442.

3. Balakumar P, Maung-U K, Jagadeesh G. Prevalence and prevention of cardiovascular disease and diabetes mellitus. Pharmacol Res 2016;113:600-9.

4. Mozaffarian D, Benjamin EJ, Go AS, et al. Executive summary: heart disease and stroke statistics - 2016 update: a report from the American Heart Association. Circulation 2016;133:447.

5. Townsend N, Wilson L, Bhatnagar P, et al. Cardiovascular disease in Europe: epidemiological update 2016. Eur Heart J 2016;37:3232-45

6. McSweeney J, Cleves MA, Fischer EP, et al. Predicting coronary heart disease events in women: a longitudinal cohort study. $J$ Cardiovasc Nurs 2014;29:482-92.

7. HCUPnet HC. Utilization project: agency for healthcare research and quality. Rockville, MD: United States Department of Health \& Human Services, 2016.

8. Canto JG, Canto EA, Goldberg RJ. Time to standardize and broaden the criteria of acute coronary syndrome symptom presentations in women. Can J Cardiol 2014;30:721-8.

9. Pepine CJ, Ferdinand KC, Shaw LJ, et al. Emergence of nonobstructive coronary artery disease: a woman's problem and need for change in definition on angiography. J Am Coll Cardiol 2015;66:1918-33.

10. Kok MM, van der Heijden LC, Sen $\mathrm{H}$, et al. sex difference in chest pain after implantation of newer generation coronary drug-eluting stents: a patient-level pooled analysis from the TWENTE and DUTCH PEERS trials. JACC Cardiovasc Interv 2016;9:553-61.

11. Choinière $\mathrm{M}$, Watt-Watson $\mathrm{J}$, Victor JC, et al. Prevalence of and risk factors for persistent postoperative nonanginal pain after cardiac surgery: a 2-year prospective multicentre study. CMAJ 2014;186:E213-23.

12. Katz J, Weinrib A, Fashler SR, et al. The Toronto general hospital transitional pain service: development and implementation of a multidisciplinary program to prevent chronic postsurgical pain. J Pain Res 2015;8:695-702.

13. King KM, Parry M, Southern D, et al. Women's Recovery from Sternotomy-Extension (WREST-E) study: examining long-term pain and discomfort following sternotomy and their predictors. Heart 2008;94:493-7.

14. Bjørnnes AK, Parry M, Lie I, et al. Pain experiences of men and women after cardiac surgery. J Clin Nurs 2016;25(19-20):3058-68.

15. Kirchberger I, Heier M, Wende R, et al. The patient's interpretation of myocardial infarction symptoms and its role in the decision process to seek treatment: the MONICA/KORA Myocardial Infarction Registry. Clin Res Cardiol 2012;101:909-16.

16. Agrawal S, Mehta PK, Bairey Merz CN. Cardiac Syndrome X: update 2014. Cardiol Clin 2014;32:463-78.

17. Pizzi C, Xhyheri B, Costa GM, et al. Nonobstructive versus obstructive coronary artery disease in acute coronary syndrome: a meta-analysis. J Am Heart Assoc 2016;5:e004185.

18. Altintas $E$, Yigit $F$, Taskintuna N. The impact of psychiatric disorders with cardiac syndrome $X$ on quality of life: 3 months prospective study. Int J Clin Exp Med 2014;7:3520-7.

19. Arthur HM, Campbell P, Harvey PJ, et al. Women, cardiac syndrome X, and microvascular heart disease. Can J Cardiol 2012;28:S42-S49.

20. Mieres $\mathrm{JH}$, Gulati M, Bairey Merz N, et al. Role of noninvasive testing in the clinical evaluation of women with suspected ischemic heart disease: a consensus statement from the American Heart Association. Circulation 2014;130:350-79.

21. Shaw LJ, Tandon S, Rosen S, et al. Evaluation of suspected ischemic heart disease in symptomatic women. Can J Cardiol 2014;30:729-37.

22. Sjöström-Strand A, Fridlund B. Women's descriptions of symptoms and delay reasons in seeking medical care at the time of a first myocardial infarction: a qualitative study. Int J Nurs Stud 2008;45:1003-10.

23. von Eisenhart Rothe AF, Albarqouni L, Gärtner C, et al. Sex specific impact of prodromal chest pain on pre-hospital delay time during an acute myocardial infarction: findings from the multicenter MEDEA Study with 619 STEMI patients. Int J Cardiol 2015;201:581-6.

24. Sabbag A, Matetzky S, Gottlieb S, et al. Recent temporal trends in the presentation, management, and outcome of women hospitalized with acute coronary syndromes. Am J Med 2015;128:380-8.

25. Mozaffarian D, Benjamin E, Go A, et al. Heart disease and stroke statistics - 2015 update. Circulation 2015;131:e1-e294.

26. Jaarsma T, Strömberg A, Mårtensson J, et al. Development and testing of the European Heart Failure Self-Care Behaviour Scale. Eur $J$ Heart Fail 2003;5:363-70.

27. Lorig KR, Holman HR. Self-management education: history, definition, outcomes, and mechanisms. Ann Behav Med 2003;26:1-7.

28. Osborne $\mathrm{RH}$, Batterham R, Livingston J. The evaluation of chronic disease self-management support across settings: the international experience of the health education impact questionnaire quality monitoring system. Nurs Clin North Am 2011;46:255-70.

29. EPPI. EPPI Centre: evidence for policy and practice information and coordinating centre. http://eppi.ioe.ac.uk/cms/ (accessed $5 \mathrm{Apr}$ 2015).

30. Oliver S, Harden A, Rees R, et al. An emerging framework for including different types of evidence in systematic reviews for public policy. Evaluation 2005;11:428-46.

31. Pope C, Mays N, Popay J. Synthesizing qualitative and quantitative health evidence. New York: McGraw Open University Press, 2007.

32. Harden A, Garcia J, Oliver S, et al. Applying systematic review methods to studies of people's views: an example from public health research. J Epidemiol Community Health 2004;58:794-800.

33. Thomas J, Harden A, Oakley A, et al. Integrating qualitative research with trials in systematic reviews. BMJ 2004;328:1010-2.

34. Miake-Lye IM, Hempel S, Shanman R, et al. What is an evidence map? A systematic review of published evidence maps and their definitions, methods, and products. Syst Rev 2016;5:1. 
35. Gaarder M. Evidence gap maps - a tool for promoting evidenceinformed policy and prioritizing future research. 625: The World Bank, 2013.

36. Bragge P, Clavisi O, Turner T, et al. The global evidence mapping initiative: scoping research in broad topic areas. BMC Med Res Methodol 2011;11:1.

37. Wang DD, Shams-White M, Bright OJ, et al. Creating a literature database of low-calorie sweeteners and health studies: evidence mapping. BMC Med Res Methodol 2016;16:1.

38. Schardt $\mathrm{C}$, Adams MB, Owens T, et al. Utilization of the PICO framework to improve searching PubMed for clinical questions. BMC Med Inform Decis Mak 2007;7:1.

39. Ballard M, Montgomery P. Risk of bias in overviews of reviews: a scoping review of methodological guidance and four-item checklist. Res Synth Methods 2017;8:92-108.

40. StataCorp. Stata statistical software: release 13. College Station, TX: StataCorp LP, 2013.

41. Adler N, Adashi E, Aguilar-Gaxiola S, et al. Women's health research: progress, pitfalls, and promise. Washington, DC: Institute of Medicine's Committee on Women's Health Research, 2010.

42. Mazure CM, Jones DP. Twenty years and still counting: including women as participants and studying sex and gender in biomedical research. BMC Womens Health 2015;15:94.

43. McSweeney JC, Rosenfeld AG, Abel WM, et al. Preventing and experiencing ischemic heart disease as a woman: state of the science: a scientific statement from the American Heart Association. Circulation 2016;133:1302-31.

44. Day S, Mason R, Lagosky S, et al. Integrating and evaluating sex and gender in health research. Health Res Policy Syst 2016;14:75.

45. Canadian Institutes of Health Research. Definitions of Sex and Gender. 2015 http://www.cihr-irsc.gc.ca/e/47830.html (accessed 6 Dec 2016)

46. Hayes SN, Wood SF, Mieres JH, et al. Taking a giant step toward women's heart health: finding policy solutions to unanswered research questions. Womens Health Issues 2015;25:429-32.

47. Pelletier R, Khan NA, Cox J, et al. Sex versus gender-related characteristics: which predicts outcome after acute coronary syndrome in the young? J Am Coll Cardiol 2016;67:127-35.

48. Lichtman JH, Froelicher ES, Blumenthal JA, et al. Depression as a risk factor for poor prognosis among patients with acute coronary syndrome: systematic review and recommendations: a scientific statement from the American Heart Association. Circulation 2014;129:1350-69.

49. Vaccarino V, Shah AJ, Rooks C, et al. Sex differences in mental stress-induced myocardial ischemia in young survivors of an acute myocardial infarction. Psychosom Med 2014;76:171-80.

50. Gahagan J, Gray K, Whynacht A. Sex and gender matter in health research: addressing health inequities in health research reporting. Int J Equity Health 2015;14:12.

51. D'Onofrio G, Safdar B, Lichtman JH, et al. Sex differences in reperfusion in young patients with ST-segment-elevation myocardial infarction: results from the VIRGO study. Circulation 2015;131:1324-32.

52. Wechkunanukul K, Grantham H, Clark RA. Global review of delay time in seeking medical care for chest pain: An integrative literature review. Aust Crit Care 2017;30:13-20.

53. Foulds HJ, Bredin SS, Warburton DE. Greater prevalence of select chronic conditions among Aboriginal and South Asian participants from an ethnically diverse convenience sample of British Columbians. Appl Physiol Nutr Metab 2012;37:1212-21.

54. Dimer L, Dowling T, Jones J, et al. Build it and they will come: outcomes from a successful cardiac rehabilitation program at an Aboriginal Medical Service. Aust Health Rev 2013;37:79-82.
55. Beckie TM. Biopsychosocial determinants of health and quality of life among young women with coronary heart disease. Curr Cardiovasc Risk Rep 2014;8:1-10.

56. Wenger NK. Clinical presentation of CAD and myocardial ischemia in women. J Nucl Cardiol 2016;23:976-85.

57. Bandura A. Self-efficacy: toward a unifying theory of behavioral change. Psychol Rev 1977;84:191-215.

58. Johnston M, Foster M, Shennan J, et al. The effectiveness of an acceptance and commitment therapy self-help intervention for chronic pain. Clin J Pain 2010;26:393-402.

59. McGillion M, Arthur H, Victor JC, et al. Effectiveness of psychoeducational interventions for improving symptoms, healthrelated quality of life, and psychological well being in patients with stable angina. Curr Cardiol Rev 2008;4:1-11.

60. Perry KN, Nicholas MK, Middleton J. Multidisciplinary cognitive behavioural pain management programmes for people with a spinal cord injury: design and implementation. Disabil Rehabil 2011;33:1272-80.

61. Naylor MR, Keefe FJ, Brigidi B, et al. Therapeutic interactive voice response for chronic pain reduction and relapse prevention. Pain 2008:134:335-45.

62. Dysvik E, Kvaløy JT, Stokkeland R, et al. The effectiveness of a multidisciplinary pain management programme managing chronic pain on pain perceptions, health-related quality of life and stages of change-A non-randomized controlled study. Int J Nurs Stud 2010:47:826-35.

63. Glombiewski JA, Hartwich-Tersek J, Rief W. Two psychological interventions are effective in severely disabled, chronic back pain patients: a randomised controlled trial. Int J Behav Med 2010;17:97-107.

64. Barr VJ, Robinson S, Marin-Link B, et al. The expanded Chronic Care Model: an integration of concepts and strategies from population health promotion and the Chronic Care Model. Hosp Q 2003;7:73-82.

65. Calkins E, Boult C, Wagner EH, et al. New ways to care for older people: building systems based on evidence: Springer Publishing Company, 2004.

66. Association $\mathrm{OH}$. Ontario ministry of health and long-term care, 2017.

67. Fawcett J, Watson J, Neuman B, et al. On nursing theories and evidence. J Nurs Scholarsh 2001;33:115-9.

68. Ryan P, Sawin KJ. The Individual and Family Self-Management Theory: background and perspectives on context, process, and outcomes. Nurs Outlook 2009;57:217-25.

69. Turk DC, Wilson HD, Cahana A. Treatment of chronic non-cancer pain. Lancet 2011;377:2226-35.

70. Tashakkor AY, Stone J, Mancini GB. Is it time to update how suspected angina is evaluated prior to the use of specialized tests implications based on a systematic review. Cardiology 2016;133:181-90.

71. Tremmel JA. To define is to limit: is that good or bad when it comes to chest pain? JACC Cardiovasc Interv 2016;9:562-4.

72. Webster R, Heeley E. Perceptions of risk: understanding cardiovascular disease. Risk Manag Healthc Policy 2010;3:49.

73. Delgado R, York A, Lee C, et al. Assessing the quality, efficacy, and effectiveness of the current evidence base of active selfcare complementary and integrative medicine therapies for the management of chronic pain: a rapid evidence assessment of the literature. Pain Med 2014;15(Suppl 1):S9-20.

74. Adams RJ, Smart P, Huff AS. Shades of grey: guidelines for working with the grey literature in systematic reviews for management and organizational studies. Int J Manag Rev 2017;19:432-54.

75. Bhattacharyya M, Stevenson F, Walters K. Exploration of the psychological impact and adaptation to cardiac events in South Asians in the UK: a qualitative study. BMJ Open 2016;6:e010195. 